\title{
REFLEKSI PEACE-EDUCATION DALAM TRANSFORMASI \\ KURIKULUM PENDIDIKAN ISLAM (Solusi Alternatif Resolusi \\ Konflik Melalui Pendidikan Formal)
}

\author{
Unik Hanifah Salsabila \\ Dosen Luar Biasa Program Studi Pendidikan Agama Islam \\ STAI Masjid Syuhada Yogyakarta \\ Email: unikhanifah14@gmail.com
}

\begin{abstract}
Abstrak
Pada konteks pendidikan Islam, kurikulum merupakan planning of learning dari tataran idea yang terbingkai dalam integritas antara hal-hal yang profan maupun sakral untuk mengkonstruk manusia menjadi hamba yang bertakwa. Adapun dialektika dan persinggungan pendidikan Islam terhadap berbagai jenis konflik kekerasan sekaligus performa kurikulum pendidikan Islam yang memegang konsep continuing education dan lifelong learning itulah, yang kemudian mengharuskan adanya upaya rekonstruksi melalui eksplorasi konsep peace building yang bersumber pada AlQur'an dan hadis. Dalam tradisi Islam klasik, konsepsi tentang peace-education tersebut telah dipraktikkan oleh Nabi sesuai dengan konteks zamannya pada waktu itu. Sehingga menjadi tugas berkelanjutan dari praktisi pendidikan untuk menderivasikan konsepsi tersebut ke dalam transformasi kurikulum pendidikan Islam praksis di lembaga pendidikan formal.
\end{abstract}

Kata kunci: Kurikulum, Peace-education, Transformasi

\section{Abstract}

Within context of Islamic education, a curriculum is a planning of learning from the level of ideas framed in the integrity between the profane and sacred things to construct human beings into pious servants. The dialectic and the interrelationship of Islamic education to the various types of violent conflict as well as the performance of Islamic education curriculum that holds the concept of continuing education and lifelong learning of which then require the existence of reconstruction efforts through the exploration of the concept of 
Unik Hanifah Salsabila : Refleksi Peace-Education dalam Transformasi Kurikulum

peace building sourced from the Qur'an and hadiths. The classical Islamic tradition declares that the conception of peaceeducation has been practiced by the Prophet according to the context of his era at that time. Therefore it becomes a continuing duty of educational practitioners to derive the conception into the transformation of Islamic education curriculum praxis in formal educational institutions.

Keywords: Curriculum, Peace-education, Transformation.

\section{A. Pendahuluan}

Kurikulum pendidikan Islam merupakan ujung tombak pembelajaran moralitas dan internalisasi nilai-nilai perdamaian bagi generasi muslim. Realita fenomena kekerasan yang masih terjadi di dunia pendidikan merupakan indikator bahwa kurikulum yang menaungi proses atau aktivitas pendidikan yang ada, masih jauh dari idealisme terkait pemahaman mendalam akan urgensi budaya peaceeducation yang lahir melalui pembelajaran Pendidikan Agama Islam di lingkup pendidikan formal, baik sekolah maupun madrasah. Kurikulum pendidikan Islam semestinya menggunakan lensa perdamaian dalam setiap upaya penafsiran ajaran Islam pada proses pembelajaran guna menangkap makna Islam yang sesungguhnya, yakni agama yang menjunjung tinggi perdamaian. Adapun muatan peaceeducation yang diderivasikan melalui kurikulum pendidikan Islam yang dimaksud, bukan merupakan proses kognitif yang mengajarkan pengetahuan atau keterampilan semata, misalnya teori perdamaian atau keterampilan negosiasi atau mediasi konflik. Melainkan lebih kepada upaya mengembangkan pola pikir dan kesadaran individu terhadap nilai-nilai keutamaan dalam kehidupan. 
Peace-education secara sederhana dapat dipahami melalui pendapat Tricia Jones, yakni a spectrum of processes that utilize communication skills and creative and analytic thinking to prevent, manage, and peacefully resolve conflict. Adapun menurut Gabriel Solomon, sebagaimana dikutip oleh H.B. Danesh menyimpulkan bahwa aktivitas peace-education berada pada empat kategori, yakni peace-education sematamata sebagai aktivitas perubahan mindset, peace-education semata-mata sebagai penanaman seperangkat kecakapan atau skill, peace-education sebagai promosi hak asasi manusia di berbagai belahan dunia, dan peace-education sebagai aktivitas pengelolaan lingkungan hidup, pelucutan senjata, dan promosi budaya damai.

Adapun dalam perspektif ajaran Islam, ayat-ayat AlQur'an dan hadis dapat dikonfirmasi kandungannya yang secara eksplisit mengandung muatan visi perdamaian Islam. Konstruksi visi perdamaian tersebut meliputi beberapa kategori seperti nilai toleransi, ajakan kepada titik temu (common platform), saling menghormati dan menghargai kepercayaan satu dengan lainnya, keutamaan dalam memberi maaf, tidak melampaui batas dalam bertindak termasuk di dalamnya aturan pemberian hukuman, dorongan untuk membantu menyelesaikan masalah atau resolusi konflik, dan perintah memerangi orang-orang yang melampaui batas dengan koridor yang sangat tegas dan jelas.

\section{B. Studi Peace Building dalam Perspektif Pendidikan}

Pendidikan Islam menjelaskan dengan rigid posisi peserta didik sebagai manusia di antara makhluk Allah lainnya, tanggung jawabnya dalam kehidupan, peranannya 
sebagai makhluk sosial dan tanggung jawabnya dalam tatanan kehidupan masyarakat, serta hubungan manusia dengan alam dan tugasnya untuk memahami hikmah penciptaan dengan cara menjaga keharmonisan. Pendidikan Islam mengarah pada dua dimensi dialektika, yakni dimensi vertikal dan horizontal. Dalam dimensi vertikal, pendidikan Islam menjadi mediator untuk memahami fenomena dan misteri kehidupan serta upayanya mencapai hubungan dengan Tuhan. Hal ini sebagaimana diungkapkan Al Ghazali, yang secara eksplisit menempatkan dua hal penting sebagai orientasi pendidikan. Pertama, mencapai kesempurnaan manusia untuk secara kualitatif mendekatkan diri kepada Allah SWT. Kedua, mencapai kesempurnaan manusia untuk meraih kebahagiaan di dunia dan akhirat.

Sedangkan dalam dimensi horizontal, pendidikan Islam diharapkan mampu mengembangkan pemahaman peserta didik dalam menghadapi realitas kehidupan, baik yang menyangkut dirinya, masyarakat atau yang kerap disebut dengan hablum min an-nas, maupun dengan semesta alam. Artinya, peserta didik tidak hanya berorientasi pada keridhaan Sang Khalik semata, tetapi juga bermakna bagi sesama manusia dan lingkungan kehidupan di sekitarnya. Oleh karena itu, konsep damai dalam pandangan Islam dapat dibagi menjadi empat bagian yang saling berhubungan satu sama lain. Pertama, damai dalam konteks hubungan dengan Allah sebagai Pencipta, yakni kedamaian yang terwujud karena manusia hidup sesuai dengan prinsip penciptaannya yang fitri. Kedua, damai dengan diri sendiri. Ketiga, damai dalam kehidupan bermasyarakat. Hal ini dapat diwujudkan jika manusia berada dalam kehidupan yang bebas dari perang 
dan diskriminasi, serta diterapkannya prinsip keadilan. Keempat, damai dengan lingkungan, terwujud dari pemanfaatan sumber daya alam bukan hanya sebagai penggerak pembangunan, melainkan pula sumber yang harus dilestarikan demi kesinambungan ekosistem kehidupan.

Al-Quran memberikan koridor yang cukup eksplisit dan praktis terkait conflict resolution. Al-Qur'an tidak hanya memberikan tips-tips praktis akan tetapi juga menggariskan beberapa prinsip yang harus menjadi dasar dari proses tersebut. Pada hokum syariat tentang qishas misalnya, terdapat batasan aturan pelaksanaan syariat yang jelas termaktub dalam Qs. 2:178-179. Dengan kata lain proses resolusi konflik dalam Islam harus menekankan pada prinsip keadilan, pemberdayaan bagi orang-orang yang lemah, serta membangun solidaritas sosial dan dukungan publik. Islam menolak segala sesuatu yang melampaui batas, termasuk dalam hal penegakan kebenaran dan pencapaian keadilan. Dalam konteks penanganan konflik modern, pada level ini dikenal berbagai tahapan resolusi konflik, yakni mulai dari gencatan senjata (ceasefire) atau penghentian kekerasan fisik, kemudian membuka ruang negosiasi antara para pihak yang berkonflik (disputant). Jika negosiasi menemui jalan buntu, maka ada upaya mediasi. Jika mediasi gagal, maka ada mekamisme peradilan atau arbitrase. Dalam bahasa Al-Qur'an upaya-upaya ini disebut dengan musyarawah (negosiasi), alashlah (mediasi), dan at-tahkim (arbitrase).

Tujuan dari peace-education dalam perspektif pendidikan Islam, tentu saja tidak hanya sekedar menyentuh dimensi kognitif semata, melainkan sampai pada dimensi praktis. Harapannya peserta didik dapat mengimplementasi- 
kan gagasan, pengetahuan, keahlian, dan nilai-nilai tersebut dalam kehidupan sehari-hari. Hal ini dikarenakan pendidikan Islam pada dasarnya menyentuh tiga domain yang saling terintegrasi. Yang pertama knowing, peserta didik mengetahui dan memahami ajaran Islam. Kedua doing, peserta didik mampu mempraktikkan ajaran Islam. Dan yang ketiga being, di mana peserta didik dapat menjalani hidup sesuai dengan ajaran agama. Bagaimanapun, pendidikan Islam tidak boleh dicukupkan pada otak (pemahaman) dan badan (simbol fisik dan perbuatan). Lebih dari itu, perlu diadakan internalisasi ajaran Islam ke dalam al-qalb (hati) dan áz-żauq (rasa). Adapun salah satu cara internalisasinya adalah dengan melakukan keteladanan dan pembiasaan.

Dalam konteks pengajaranya, seorang pendidik bukan berposisi sebagai hakim yang keputusannya bersifat mutlak. Bukan pula sebatas pembimbing dalam perjalanan belajar maupun perpanjangan tangan dari ilmu-ilmu dan ajaran ulama terdahulu. Pendidik dalam perspektif pendidikan Islam merupakan pewaris para Nabi, tidak hanya pewaris ilmu-ilmu Nabi tetapi juga pewaris sifat-sifat Nabi. Di antaranya, patut menjadi contoh dalam kepemilikan semangat perjuangan terhadap Islam, bukan perjuangan dengan paksaan dan kekerasan melainkan dengan hikmah, kelembutan, dan kasih sayang serta memberikan pendidikan terhadap umat dengan gerakan pembaharuan agar menjadi yang lebih baik dalam segala bidang demi kemajuan umat.

Adapun dalam literatur Barat, istilah peace-education bukan merupakan hal baru karena sudah banyak penulis yang mengkaji dan mengembangkan gagasan maupun aksi pendidikan menggunakan konsepi tersebut. Ada beberapa 
definisi yang dikemukakan terkait peace-education, di antaranya menurut versi UNICEF. Badan PBB yang secara khusus menangani pendidikan ini mendefinisikan peaceeducation sebagai proses mempromosikan pengetahuan, keahlian-keahlian, sikap, dan nilai-nilai yang diperlukan untuk membawa perubahan perilaku yang memungkinkan anak-anak, pemuda, dan orang dewasa untuk mencegah (to prevent) konflik dan kekerasan, menyelesaikan (to resolve) konflik secara damai, dan menciptakan (to create) kondisi yang kondusif bagi perdamaian, baik pada level antar personal, interpersonal, antar kelompok, nasional, maupun internasional.

Elise Boulding menyatakan bahwa upaya membangun peace-education yang dilakukan secara berkelanjutan akan menghasilkan budaya damai. Budaya damai ini pertama-tama dapat ditemukan di dalam lingkup keluarga. Dalam hal ini orang tua khususnya seorang ibu, memiliki peranan strategis dalam rangka mendidik dan menumbuhkan budaya damai melalui lingkup keluarga, sebagaimana pernyataannya berikut ini:

"The familial household is an important source of peace culture in any society. It is there that women's nurturing culture flourishes. Traditionally, women have been the farmers as well as the bearers and rearers of children, the feeders and healers of the extended family. The kind of responsiveness to growing things-plants, animals, babies - that women have had to learn for the human species to survive is central to the development of peaceful behavior." 
Menurutnya, anak-anak akan belajar dari orang tua mereka bagaimana cara menangani konflik, dan bagaimana mereka harus bersikap terhadap orang lain yang memiliki tampilan berbeda. Oleh karena itu, struktur serta pola asuh keluarga yang kurang tepat dapat menjadi salah satu faktor pemicu pembiasaan kekerasan dan pendidikan kekerasan bagi anggota-anggotanya. Untuk menjadikan peace-education sebagai sebuah budaya dan paradigma baru dalam dunia pendidikan diperlukan upaya memperkenalkan konsep peaceeducation sedini mungkin, baik melalui lingkungan keluarga maupun lingkungan pendidikan formal dengan menggunakan seperangkat kurikulum.

Dalam praktiknya Ahmad Baedowi menyatakan, untuk mengajarkan budaya damai di suatu lembaga pendidikan, perlu dipertimbangkan untuk memasukkan agenda keragaman budaya dan etnik ke dalam kurikulum sekolah. Hal ini dikarenakan adanya kebutuhan instingtif siswa dalam memandang perbedaan, sehingga kebutuhan muatan budaya dan etnik dalam kurikulum formal juga akan meminimalisir pemahaman siswa terhadap monopoli makna kebenaran secara sepihak. Selain itu, muatan keragaman budaya dan etnik dalam kurikulum pendidikan juga dapat mengubah dan menambah respons pedagogis pendidik dalam mengajar. Jika pendidik memiliki kepekaan budaya dan etnik yang kuat, respons pedagogisnya akan meningkat dengan sendirinya. Melalui pendekatan muatan kurikulum berbasis budaya, respons pedagogis pendidik terhadap peserta didik juga akan berbeda, sehingga membantu peserta didik dalam mengaksentuasi keragaman budaya di lingkungan mereka masing-masing. 
Unik Hanifah Salsabila : Refleksi Peace-Education dalam Transformasi Kurikulum

\section{Strategi Implementasi Peace-education dalam Pengembangan Kurikulum Pendidikan Islam}

Hingga saat ini konsep peace-education masih menjadi wilayah diskursus kontemporer yang belum menemukan kesepakatan utuh mengenai pemaknaan sifat damai dan penciptaan konsep dari perdamaian itu sendiri. Secara teknis hal tersebut diperlukan untuk membentuk kerangka kerja terstruktur dalam setiap program peace-education yang komprehensif dan efektif, sehingga dapat mempertemukan tujuan-tujuan peace-education yang berbeda pada setiap kultur pendidikan di berbagai tempat. Akan tetapi meski belum ada universalisasi yang disepakati terkait pendekatan yang digunakan dalam menentukan standar program peaceeducation, dapat dipahami bahwa ide besar dari konsepsi peace-education bertujuan untuk membantu peserta didik mencapai pemikiran bahwa perdamaian adalah jalan kehidupan dan kultur universal yang memiliki kontribusi untuk mengembangkan landasan kerja sama dengan masyarakat dan budaya yang berbeda.

Pada konteks ini, pendidikan menjadi dasar pembentukan kultur perdamaian dalam diri peserta didik. Sehingga peace-education memberikan pemahaman utuh kepada peserta didik mengenai bagaimana akar dari kekerasan untuk kemudian diberikan pengetahuan baru tentang isu kritis sebagai solusi alternatif, yakni dengan cara menjaga perdamaian (peace keeping), menciptakan perdamaian (peace making), dan membangun perdamaian (peace building). Abdurrahman Assegaf yang meneliti tentang pendidikan tanpa kekerasan, menyatakan bahwa model peaceeducation selain memiliki materi dan metode juga 
memiliki metode instruksional yang dapat diaplikasikan untuk semua jenjang pendidikan. Ia menjelaskan maksud dari model instruksional adalah sebagai acuan bagi proses pembelajaran yang sedang dilakukan. Untuk menerapkannya Abdurrahman Assegaf menambahkan bahwa diperlukan pengolahan kelas, melakukan interaksi belajar-mengajar, penyampaian materi dan metode, yang semuanya menerapkan pendekatan humanistik (human approach) di mana antara pendidik dan peserta didik terdapat komunikasi multi-arah sehingga tercipta suasana demokratis di dalam kelas. Dalam pendekatan ini, peran guru tidak mendominasi secara berlebihan. Pelaksanaan model tersebut memerlukan persiapan fasilitas sederhana, seperti ruang belajar yang fleksibel dan suasana yang kondusif.

Banyak metode yang bisa digunakan dalam praktikpraktik peace-education di sekolah. Misalnya melalui kurikulum yang diajarkan secara resmi, kegiatan ekstrakurikuler, aktifitas seni budaya dan dialog-dialog yang bertemakan perdamaian. Sasaran utama dari setiap aktifitas yang dijalankan adalah siswa, selain komunitas sekolah secara umum, yaitu guru, kepala sekolah atau komite sekolah. Praktik peace-education tersebut perlu mendapat perhatian khusus di dunia pendidikan Islam sehingga visi perdamaian yang sudah melekat dalam ajaran Islam dapat direpresentasikan dengan utuh melalui kegiatan pembelajaran. Realitanya visi tentang peace-education belum sepenuhnya dipahami atau dijiwai oleh para pendidik dan penanggungjawab kurikulum. Sebagian besar pendidik hanya berupaya menyampaikan pesan perdamaian itu sebagai bagian dari pencapaian materi atau ketuntasan belajar, 
namun belum membangunnya dalam konsep budaya dan paradigma. Oleh karena itu diperlukan beberapa strategi untuk mengkondisikan peace building secara massif, yakni sebagai berikut:

1. Merancang kurikulum pembelajaran tematik yang terintegrasi. Pembelajaran tematik merupakan salah satu model pembelajaran kontekstual yang didasarkan pada hasil penelitian John Dewey (1916) yang menyebutkan bahwa siswa akan belajar dengan baik jika apa yang dipelajari terkait dengan apa yang telah diketahui dan dengan kegiatan atau peristiwa yang akan terjadi di sekelilingnya. Pembelajaran ini menekankan pada daya pikir yang tinggi, transfer ilmu pengetahuan, mengumpulkan, dan menganalisis data, memecahkan masalah-masalah tertentu baik secara individu maupun kelompok. Dalam konteks ini, tentunya peserta didik dapat dihadapkan langsung pada realitas masyarakat yang ada di sekitar mereka untuk kemudian merancang solusi berbasis peace-education dengan melibatkan berbagai bidang keilmuan yang dipelajari di sekolah.

2. Mengupayakan pola komunikasi nirkekerasan dalam lingkup pendidikan formal. Komunikasi nirkekerasan dapat terbangun melalui penggunaan kata-kata yang positif pada setiap interaksi yang terjadi di lingkungan pendidikan, seperti pembiasaan kata-kata terimakasih, tolong, dan lain sebagainya di sekolah.

3. Menciptakan pendidikan yang demokratis. Pendidikan yang demokratis berarti melibatkan peserta didik secara aktif dalam segala aktivitas di lembaga pendidikan. Hal ini akan mampu menciptakan komunikasi yang baik antara 
pendidik dengan peserta didik dalam proses pendidikan dengan tetap mengupayakan monitoring atau pengawasan terhadap segala aktivitas pendidikan yang terjadi di sekolah.

4. Mendorong literasi peace-education di kalangan pendidik agama Islam. Pendidik harus dibekali pengetahuan yang luas dan mendalam terkait isu kontemporer dalam teori maupun praktik peace-education serta pengkajiannnya dalam perspektif Al-Qur'an dan hadis. Sehingga pendidik dapat merepresentasikan konsep peace-education dalam setiap kegiatan pembelajaran di kelas maupun di luar kelas secara komprehensif.

\section{Penutup}

Konstruksi visi perdamaian yang komprehensif dalam konsep peace-education sudah termuat secara eksplisit di dalam Al-Qur'an dan hadis yang merupakan postulat utama bagi kurikulum pendidikan Islam. Adapun wacana peaceeducation juga mempunyai tujuan yang relevan dengan

eksistensi kurikulum pendidikan Islam, yakni mengembangkan fitrah peserta didik, baik ruh, fisik, kemauan, dan akalnya secara dinamis sehingga terbentuk pribadi yang bertakwa dengan menjadikan Al-Qur'an, khususnya konsep perdamaian yang terkandung di dalamnya, sebagai sebuah paradigma utuh pada setiap aktivitas kehidupan.

Praktisi pendidikan dan pengembang kurikulum harus menyadari bahwa pendidikan formal merupakan mediator yang efektif dalam membentuk karakter nirkekerasan sejak dini, dan dalam hal ini pendidikan Islam menjadi ujung 
Unik Hanifah Salsabila : Refleksi Peace-Education dalam Transformasi Kurikulum

tombak dari segala bentuk internalisasi nilai dan moralitas bagi peserta didik muslim. Mengingat urgensi peace-education sebagai upaya resolusi konflik, maka sudah semestinya jika lembaga pendidikan Islam mengambil peranan utama sebagai pilot project pengembangan kurikulum peace-education yang berbasis pada Al-Quran dan Hadits. 


\section{DAFTAR PUSTAKA}

Assegaf, Abd. Rahman, Pendidikan Tanpa Kekerasan: Tippologi Kondisi, Kasus, dan Konsep, Yogyakarta: Tiara Wacana Yogya, 2004.

Baedowi, Ahmad, "Pendidikan Damai dan Resolusi Konflik untuk Sekolah” dalam Media Indonesia, Senin, 1 Maret 2010.

Danesh, H.B., "Towards an Integrative Theory of Peace Education" dalam Journal of Peace Education, Volume 3, Nomor 1, 2006.

Idi, Abdullah dan Toto Suharto, Revitalisasi Pendidikan Islam, Yogyakarta: Tiara Wacana, 2006.

Khum, Ghadir, "Landasan Filosofis Pendidikan Damai" dalam http://www.scribd.com, diakses pada tanggal 26 Oktober 2017.

Majid, Abdul dan Dian Andayani, Pendidikan Agama Islam Berbasis Kompetensi, Konsep dan Implementasi Kurikulum 2004, Bandung: Remaja Rosda Karya, 2004.

M. Hess, Kären, dkk, Juvenile Justice, USA: Sara Dovre Wudali, Buuji Inc., 2013.

Muhaimin, Rekonstruksi Pendidikan Islam: Dari Paradigma, Manajemen Kelembagaan, Kurikulum hingga Strategi Pembelajaran, Jakarta: Rajawali, 2009.

Ramsbotham, Oliver Tom Woodhouse and Hugh Miall, Conflict Resolution, USA: Cambridge UK and Polity Press Malden, 2007. 